\title{
LAS CONSECUENCIAS DE LAS DECISIONES DEL CONSTITUYENTE EN LAS FINANZAS PÚBLICAS: EL CASO DE LAS JURISDICCIONES PARALELAS
}

\section{Daniel Gallegos Herrera*}

RESUMEN: El artículo critica la falta de cuidado del constituyente al diseñar la institucionalidad desde la perspectiva de la eficiencia y eficacia del gasto público. Identifica el fenómeno de expansión de las garantías jurisdiccionales de los derechos constitucionales en el Ecuador como un proceso de fragmentación del discurso jurídico de la relación ciudadanoEstado -objeto de control de la jurisdicción contencioso-administrativa-. Por último, explora las consecuencias negativas de este fenómeno de redundancia respecto del dinero disponible para el Estado y los ciudadanos.

PALABRAS CLAVE: Garantías jurisdiccionales; amparo; acción de protección; jurisdicción contencioso-administrativa; fragmentación; eficiencia; eficacia; gasto público; diseño institucional.

\section{THE FINANCIAL CONSEQUENCES OF THE CONSTITUENT'S DECISIONS: THE CASE OF PARALLEL JURISDICTIONS}

ABSTRACT: The article criticizes the lack of care constituent assemblies display when designing institutions from the perspective of the principles of efficiency and efficacy of public expenditure. It identifies the phenomenon consisting on the expansion of special judicial remedies for constitutional rights in Ecuador as a process of fragmentation of the legal discourse concerning the relationship Citizen-State -which is also the object matter of administrative jurisdiction-. Finally, it explores the negative consequences of the phenomenon of redundancy in terms of the economic resources that are available for the State and the citizens.

KEYWORDS: Judicial remedies; constitutional protection; administrative jurisdiction; fragmentation; efficiency; efficacy; public expenditure; institutional design.

\section{Introducción}

Un símil de gran utilidad para comprender las actuaciones del constituyente al momento de redactar un nuevo texto que ordene la organización político-administrativa de un Estado consiste en comparar el proceso constituyente con una borrachera. Los procesos de

\footnotetext{
* Alumno del programa de Doctorado en Derecho por la Universidad Andina Simón Bolívar - Sede Ecuador. Master of Laws en perfil de Derecho Público e Internacional por la Universidad de Melbourne - Australia. Especialista superior en Derecho Constitucional por la Universidad Andina Simón Bolívar - Sede Ecuador. Licenciado en Ciencias Jurídicas y abogado de los tribunales de la República por la Pontificia Universidad Católica del Ecuador. Docente invitado en el módulo "Teoría del Estado" en el Instituto de Altos Estudios Nacionales - Centro de Derechos y Justicia - Ecuador. Docente invitado en el módulo "Principios constitucionales aplicables al Derecho Notarial y Registral" en la Falcultad de Jurisprudencia de la Universidad Católica Santiago de Guayaquil. Actualmente, coordinador técnico de sustanciación, y previamente coordinador técnico de selección en la Secretaría Técnica Jurisdiccional de la Corte Constitucional del Ecuador. Previamente, coordinador de despacho de jueza constitucional y asesor en la Corte Constitucional del Ecuador. Dirección electrónica: dan_gahe@hotmail.com.
} 
formulación de constituciones están marcados por una suerte de autopercepción de omnipotencia, ocasionada por la libertad de acción conferida al órgano encargado del diseño del nuevo texto constitucional. Si se deja que dicha autopercepción se imponga sobre la prudencia, la situación puede desembocar en la formulación de promesas basadas en la premisa de la dilapidación. El problema surge cuando se debe pagar las cuentas, lo que sin duda agudiza la resaca al día siguiente.

El objeto del presente trabajo es poner en cuestión el poco cuidado del constituyente ecuatoriano en considerar los recursos que el Estado está en la capacidad de obtener, y la forma más eficiente y eficaz para conseguir sus fines, cuando diseña el arreglo constitucional -luego, sumamente difícil de revertir por la rigidez que adquiere-. El trabajo aborda el tema con una actitud posmoderna en relación al Derecho, (Gallegos Herrera 2018; Eco y Eco 2011; Koskenniemi 2011c) ${ }^{1}$ sin desconocer la importancia y la necesidad de la protección judicial de los derechos constitucionales y de aquellos que constituyen expresiones de su desarrollo en normas de inferior jerarquía. Más aún, el trabajo cuestiona la deficiencia en términos de garantías de un procedimiento contencioso-administrativo que tiene solo un par de décadas más que las acciones constitucionales correspondientes y que hasta la fecha refleja muestras de no consolidarse como un escudo eficaz para oponerse a la arbitrariedad en el ejercicio del poder público. Sin embargo, el análisis se cuida de ceder sin cuestionamientos a la falacia que subyace en el discurso según el cual, a más acciones de garantía, mayor protección. Bien lo señalan Holmes y Sustein:

... una teoría de los derechos que nunca descendiera de las alturas de la moral al mundo de los recursos escasos sería penosamente incompleta, incluso desde un punto de vista moral. Puesto que "deber implica poder", y la falta de recursos implica no poder, probablemente los teóricos morales deberían prestar más atención a los impuestos y al gasto público de la que suelen concederles (Holmes y Sunstein 2012, 36).

El proceso constituyente, como aquel en el cual -al menos en teoría-, los diversos actores buscan los acuerdos mínimos de la "moral" de la comunidad política organizada,

\footnotetext{
${ }^{1}$ En el trabajo citado se define dicha actitud como “... [e]l examen crítico del fenómeno jurídico, no con el objeto de abandonar las esperanzas en él, sino en reconocer sus limitaciones y sus potencialidades [...] implica definir de forma precisa el objeto de estudio [...]; examinar a fondo y de forma crítica todos los elementos del fenómeno, hasta encontrar sus aporías; encontrar las causas y consecuencias de las inconsistencias y contradicciones encontradas; y, sobre todo, no ceder ante la tentación de quedarnos en la inocencia acrítica, o abandonarnos en el cinismo destructivo". El artículo construye una postura epistemológica desde la obra de Eco, quien habla de lo posmoderno en el arte, como una forma de operar, consistente en revisitar el pasado, pero con ironía y sin inocencia; así como, la de Koskenniemi, quien propone una cultura del formalismo, como una opción de reivindicar el derecho y las forma que en él imperan, como un mecanismo para generar resistencia ante el abuso del poder camuflado en discursos basados en la defensa de fines moralmente encomiables.
} 
debería considerar, entonces, que las decisiones constituyentes tienen repercusión en términos de recursos disponibles y necesidades inagotables.

En este marco, el examen se centrará en el diseño del régimen procesal orgánico y funcional de las garantías jurisdiccionales de los derechos constitucionales en el Ecuador más concretamente, el amparo constitucional, que posteriormente se reconfiguró en tres procesos: la solicitud de medidas cautelares autónomas, la acción de protección y la acción extraordinaria de protección-, en contraste con uno de los varios regímenes con los que ellas pueden hallar puntos de intersección: la jurisdicción contencioso-administrativa. ${ }^{2}$ Este fenómeno puede ser identificado, mutatis mutandis, con lo que Martti Koskenniemi identifica en el ámbito del derecho internacional como la fragmentación del discurso jurídico en léxicos marcados por el descentramiento estructural (Koskenniemi 2011d). El problema que se deriva de dicho proceso es que gran parte de las decisiones -políticas- sobre cómo y bajo qué términos debe operar el derecho en determinada situación, adopta la forma de un conflicto entre jurisdicciones; y, la estrategia de los operadores jurídicos está marcada por la búsqueda del foro que mejor atienda su pretensión, conforme a su ubicación en el descentramiento estructural del discurso jurídico. El presente trabajo sostiene que la fragmentación entre la justicia constitucional y la justicia ordinaria es un fenómeno que, entre sus consecuencias, atenta contra la efectividad y eficiencia en el gasto público.

El trabajo iniciará con la calificación de la formación de jurisdicciones paralelas como una expresión del fenómeno, denominado en el Derecho Internacional, como fragmentación del discurso jurídico. Acto seguido, entrará a determinar si la emergencia y expansión de las garantías jurisdiccionales en el Ecuador responde o no a un proceso de fragmentación, en lo que tiene que ver con la relación jurídica ciudadano-Estado, por lo que consideramos, es una interpretación inadecuada del mandato imperativo, nacido de la adopción de normas convencionales en el orden internacional -más concretamente, el artículo 25.1 de la Convención Americana sobre Derechos Humanos-. Por último, se centrará en las consecuencias previsibles de la existencia de las jurisdicciones paralelas en relación a la obligación implícita del Estado de aumentar ingresos y la obligación constitucionalmente establecida de destinarlos a un gasto que, en los hechos, resulta redundante.

\footnotetext{
${ }^{2}$ El mismo argumento podría ser intentado respecto de varios otros regímenes, como por ejemplo el contenciosofiscal. Más aún, como se examinará más adelante, en el último proceso constituyente, las garantías experimentaron una expansión en cuanto a la legitimación pasiva a actos y omisiones de particulares, así como en cuando a su carácter reparativo. Ello hace que las posibles intersecciones se den respecto de más campos, como el derecho civil, penal, laboral, u otros.
} 


\section{La fragmentación del discurso jurídico y su presencia en el derecho interno}

Martti Koskenniemi parte de la premisa del derecho como un conjunto de prácticas sociales que se traduce en un lenguaje profesional, para al fenómeno de fragmentación del Derecho Internacional. En "The Politics of international Law - 20 Years Later", define la fragmentación como un proceso que el discurso jurídico internacional ha transitado en las últimas décadas (Koskenniemi 2011d, 64 a 65). El autor parte de la noción post-estructuralista del lenguaje según la cual existe una imposibilidad estructural del derecho de ofrecer plena certeza, debido a la indeterminación material de sus contenidos $-\mathrm{O}$, visto desde la perspectiva del estructuralismo lingüístico, la contingencia de la relación entre significantes y significados-(Laclau 2004, 15), y la necesidad de llenar con una decisión política lo que el derecho no puede proveer por sí solo (Koskenniemi 2011a, 38 a 40; Gallegos Herrera 2018, 8). En palabras de Ernesto Laclau, esto se explica - en el contexto más amplio de la disputa política- del siguiente modo:

... la noción de 'discurso' como una totalidad significativa [...] trasciende la distinción entre lo lingüístico y lo extra-lingüístico. Como hemos visto, la imposibilidad de una totalidad cerrada desliga la conexión entre significante y significado. En ese sentido, hay una proliferación de 'significantes flotantes' en la sociedad, y la competencia política puede ser vista como intentos de las fuerzas políticas rivales de fijar parcialmente esos significantes a configuraciones significantes particulares [...]. Esta fijación parcial de la relación entre significante y significado es lo que se denomina en estos trabajos 'hegemonía' (Laclau 2004, $14)$.

La noción de hegemonía utilizada por los autores recuerda en mucho, y puede ser atribuida a quien ostenta mayor capital social, en los términos utilizados por Pierre Bourdieu, y descritos por su traductor como “... [aquel] que viene referido a una forma de riqueza que [...] tiene que ver con [...] la acumulación de conocimiento, prestigio, reputación, títulos académicos, favores o autoridad" (Bourdieu 2000, 167. Nota del traductor). Así, Bourdieu se refiere a la naturaleza y el alcance hegemónico de las decisiones judiciales, y describe lo que está en juego al momento de disputar el dominio sobre el campo jurídico:

Las decisiones judiciales, mediante las cuales se distribuyen diferentes volúmenes de diferentes clases de capital a los diferentes agentes (o instituciones), ponen término o al menos fijan un límite a la lucha, al intercambio o a la negociación [...] sobre todo el trabajo práctico de worldmaking [...]. El derecho es, sin duda, la forma por excelencia del poder simbólico de nominación que crea cosas nombradas [...].

El derecho es la forma por excelencia del discurso actuante capaz, por virtud propia, de producir efectos (Bourdieu 2000, 198). 
Para Koskenniemi, las características del discurso jurídico así descrito hacen que paulatinamente se vayan escindiendo discursos particulares fragmentados -0 , como diría Bourdieu, subcampos- (Bourdieu 2000, 192), los cuales no son sino lenguajes profesionales especializados, marcados por una suerte de parcialización o descentramiento estructural structural bias-, que tiene repercusiones en el orden institucional (Koskenniemi 2011d, 64). De acuerdo con el autor, la falta de coherencia intrínseca del Derecho en tanto argumento que a la vez trata de despojarse de lo político, cayendo siempre en aquello de lo que quiere escapar, desemboca en una indeterminación irresoluble sobre su contenido material (Koskenniemi 2011d, 64 a 65). Sin embargo, señala, esta indeterminación no produce resultados aleatorios, sino que los discursos fragmentados, marcados por el descentramiento estructural, son en realidad muy predecibles (Koskenniemi 2011d, 64; Marks 2010, 1 a 22).

Indica que la fragmentación del discurso jurídico propicia la emergencia de regímenes de Derecho, definidos por un acervo de conocimientos y de experiencia determinada, y por un condicionamiento cognitivo específico de los profesionales que operan inmersos en cada uno de ellos -como por ejemplo, el Derecho Comercial, Derecho de los derechos humanos, Derecho de la seguridad, Derecho Penal Internacional, Derecho Comunitario europeo, entre otros- (Koskenniemi 2011d, 64 a 65; Gallegos Herrera 2016). El descentramiento estructural de cada uno de los lenguajes fragmentados hace que los usuarios natos de cada uno de ellos encuentren soluciones jurídicas divergentes a un mismo caso.

Estas soluciones, a pesar de basarse en lenguajes irreductiblemente indeterminados, no se hallan dispuestas al azar, ya que el descentramiento estructural de los discursos fragmentados hace que la asignación de significado a las normas jurídicas dependa de la hegemonía en cada uno de los subcampos. Laclau, nuevamente en el contexto de la disputa política por el discurso, lo describe del siguiente modo:

... [L]a deconstrucción muestra que las diversas conexiones posibles entre elementos de la estructura son, en sus propios términos, indecidibles. Sin embargo, ya que una configuración ha sido actualizada por sobre las otras posibles, de esto se desprende: (1) que la configuración realmente existente es esencialmente contingente; (2) que no puede ser explicada por la propia estructura, sino por una fuerza que tiene que ser parcialmente externa a la estructura. Éste es el rol de la fuerza hegemónica. La 'hegemonía es una teoría de las decisiones tomadas en un terreno indecidible. La conclusión es, como muestra la deconstrucción, que [...] la objetividad y el poder se hacen indistinguibles (Laclau 2004, 14$15)$. 
El autor sostiene que la fragmentación tiene por efecto una parcelación de la práctica jurídica y de la institucionalidad del Derecho en campos altamente especializados, en los que los operadores dan prioridad a determinados intereses, defienden distintas escalas de valor, y producen resultados distintos. A su vez, la fragmentación determina las estrategias de las abogadas y abogados, a quienes se les ofrece un menú de jurisdicciones, del que pueden escoger aquella -o aquellas- que mejor satisfaga el interés que defienden en el caso concreto. Así, el centro del debate jurídico ya no es la sustancia del Derecho -la cual, como hemos dejado indicado, está marcada por una indeterminación irreductible-, sino que se centra en los conflictos sobre la competencia material entre discursos que, sobre un mismo tema, ofrecen resultados distintos, que bien pueden resultar discordantes o hasta contradictorios (Koskenniemi 2011d, 64 a 65).

En "International Law and Hegemony: a Reconfiguration", el autor resalta que el proceso de fragmentación tiene tres expresiones sintomáticas: Primero, la interpretación heterodoxa del Derecho. Ella implica la ampliación o modificación de estándares para determinar el sentido del Derecho y la valoración jurídica de los hechos (Koskenniemi 2011b, 228). Este tipo de fragmentación se evidencia cuando los lenguajes fragmentados incorporan calificaciones adicionales a las presentes en el derecho general, con la justificación de dotar de mayor contexto a la interpretación de la norma jurídica.

Segundo, está la institucionalización de excepciones firmes respecto del Derecho general. Este síntoma se expresa cuando, lo que en el régimen general se consiente como una excepción -a veces, una excepción en el sentido más fuerte de la palabra-, en los regímenes fragmentados se transforma en la regla (Koskenniemi 2011b, 228). Al invertir la relación regla-excepción, las soluciones que ofrece el derecho se vuelven altamente contextuales, atentan contra las aspiraciones de igualdad y universalidad que constituyen la promesa del Derecho, y pueden transformar la realidad cotidiana en un constante estado de excepción.

Tercero, tenemos la contraposición de regímenes específicos, que regulan un mismo asunto (Koskenniemi 2011b, 229). Respecto de este tipo de fragmentación, los mismo hechos pueden verse como aptos para ser conocidos y juzgados por regímenes que ofrecen soluciones discordantes, marcadas por opciones -en el fondo- políticas, las cuales provienen de regímenes institucionales de expertos que ya no reclaman su legitimidad en términos democráticos, sino de pericia en el manejo del discurso en cuestión -lo que el autor denomina gerencialismo, o managerealism, en su lengua original-(Koskenniemi 2011d, 71 a 74). Así, 
por ejemplo, un problema de salud pública puede a la vez ser un problema comercial o de propiedad intelectual - como el caso de importación de fármacos o la titularidad de los derechos para producirlos, comercializarlos o distribuirlos-; un mismo hecho puede ser visto como un asunto de derechos humanos o como uno de derecho internacional humanitario como las detenciones efectuadas durante procesos de ocupación militar de un territorio-, entre otros ejemplos. El resultado de la contraposición de regímenes es recentrar la discusión en cuestiones de jurisdicción y competencia para resolver el asunto, en lugar de cuestiones relacionadas con las pretensiones de fondo.

El riesgo que comporta la fragmentación del discurso jurídico no se halla únicamente en la pluralidad de discursos, ni en la existencia de diversos entramados institucionales dispuestos a defender su descentramiento estructural específico. Es además que, al depender de quién ostente la hegemonía en determinado discurso fragmentado, el descentramiento estructural se acentuará para favorecer determinados intereses; $\mathrm{y}$, en la disputa por la asignación de significados, el discurso fragmentado tras del cual estén los intereses con mayor influencia y recursos ejercerá una suerte de fuerza gravitacional respecto del discurso jurídico general, colonizándolo, reformulándolo a su imagen; y, por lo tanto, modificando -tal vez de forma permanente- su descentramiento estructural. Es así que "[las versiones mayoritarias de la historia que llevó [...] al presente estado del derecho raramente toman en consideración otras perspectivas más allá de aquella que el discurso jurídico dominante provee]" (Gallegos Herrera 2016, 121). ${ }^{3}$ En tal sentido, como una luz que se proyecta sobre determinado objeto, mientras más focalizada se encuentra, más áreas deja en las sombras.

En otro trabajo, se ha discurrido sobre la viabilidad de aplicar el estructuralismo crítico de Koskenniemi en el ámbito interno. En ese caso, el argumento se centró en la propuesta de una cultura del formalismo, a la que este autor identifica como una actitud posmoderna, ante la imposibilidad del Derecho de ofrecer por sí mismo soluciones basadas en nociones materiales de justicia, que a la vez sean concretas y normativas (Gallegos Herrera 2018). La fragmentación, en tanto un fenómeno que lleva las grietas estructurales del lenguaje jurídico al plano institucional, es también un fenómeno que puede ser experimentado en el contexto del derecho interno, en el que el proceso de constitucionalización del ordenamiento jurídico (Ferrajoli 2007) ha hecho muy poco por reducir el grado de indeterminación del derecho y

\footnotetext{
${ }^{3}$ El texto original, en lengua inglesa, escrito en el contexto particular del derecho de protección de inversión extranjera, señala: “... the mainstream versions of the history that led the international community to the present state of the law rarely take into account other perspectives than the one that [the dominant] legal discourse provides"
} 
dotarlo de contenidos de justicia materiales firmes, y -como es el argumento principal del presente trabajo- ha propiciado la emergencia de la justicia constitucional, basada en la aparente dicotomía entre los “asuntos constitucionales” y “asuntos de mera legalidad”.

\section{El nacimiento y expansión de la garantía jurisdiccional del amparo constitucional como expresión de la fragmentación del discurso jurídico}

En el Ecuador, al igual que en el resto de las repúblicas latinoamericanas, el constituyente ha adoptado mecanismos jurisdiccionales destinados a la protección de los derechos constitucionales, de forma paralela a los procedimientos jurisdiccionales ordinarios (Zabala Egas 2001). Además de la acción de hábeas corpus -la cual vio la luz en la Constitución de 1929 y, hasta la promulgación del texto constitucional actualmente vigente estaba a cargo de las autoridades municipales- (Ávila Linzán 2011), los procesos de garantía jurisdiccional de los derechos constitucionales fueron adoptados y cobraron fuerza a partir de la segunda mitad de la década de los noventa. En concreto, el recurso de amparo constitucional -el cual luego pasaría a denominarse acción de amparo constitucional- fue establecido con las reformas constitucionales introducidas en 1996 (Constitución Política de la República del Ecuador 1996, artículo 31). El mecanismo fue modificado en 1998 (Constitución Política de la República del Ecuador 1998, artículo 95), y reemplazado en 2008. Las reformas a esta garantía se centraron en expandir sus presupuestos de actuación, ampliar la posibilidad de intervención de la judicatura que la conoce y resuelve, y por su escisión en tres mecanismos, actualmente denominados "solicitud de medidas cautelares", “acción de protección” y "acción extraordinaria de protección” (Constitución de la República del Ecuador 2008, artículos 87, 88 y 94).

Desde sus inicios, un sector del gremio de los abogados atribuyó la expansión de la justicia constitucional a una respuesta a las patologías identificadas en el funcionamiento de la justicia ordinaria en general, y más concretamente, de la jurisdicción en materia contenciosoadministrativa. Santiago Andrade Ubidia, por ejemplo, hizo notar la discusión presente en la Función Judicial en el año 2000, en los siguientes términos:

En la Función Judicial existe un debate interno innegable entre quienes son detractores de la acción de amparo y entre quienes la defendemos [...] muchos le conciben como una instancia excepcional destinada a enervar las acciones judiciales o a imposibilitar que se inicien acciones judiciales, porque indudablemente, en el momento en que se pronuncia una acción de amparo, hay una resolución, y que no cabría otra acción. 
Por ejemplo una de las cosas que más se observa es que una gran cantidad de casos que deberían ir a la jurisdicción de lo contencioso administrativo -hay muchos ejemplos de acciones ilegales de personal, etc.- se van por la vía de amparo y entonces, cuando se declara la inconstitucionalidad de estos actos administrativos, como que las cosas se paralizan y no se vuelve a discutir más sobre el tema. Entonces, hay una sensación de que se está creando un sistema judicial paralelo, sumarísimo y en el cual no se están brindando las garantías suficientes del debido proceso en toda su amplitud [sic] (Andrade Ubidia 2001, 71 a 109).

En ese sentido, la justicia constitucional fue presentada como paralela a la contencioso-administrativa, diseñada para remediar las violaciones estructurales al derecho al acceso a la justicia y a la tutela judicial efectiva, producidas por un régimen de administración de justicia que no había podido dejar su herencia de tratar al poder público como inmune al control de su actuación. Como un breve antecedente histórico, es necesario considerar que, hasta la promulgación de la Constitución Política de la República del Ecuador de 1967, no existía control judicial de la actuación administrativa a cargo de los tribunales distritales con competencia en la materia. Esta Constitución preveía la existencia de tribunales de lo contencioso administrativo y tributario, centralizados en Quito, con jurisdicción nacional (Constitución Política de la República del Ecuador 1967, artículo 213). Con base en dicha disposición constitucional, en 1968 fue promulgada la (Ley de la Jurisdicción Contencioso Administrativa 1968), la cual siguió vigente con reformas hasta el año 2015, cuando fue promulgado el (Código Orgánico General de Procesos 2015).

En ocasión de los comentarios al precepto contenido en el artículo 173 de la Constitución de la República, José Vicente Troya hace un recuento de los principales cambios operados en la administración de justicia en materia administrativa en el Ecuador:

El precepto [contenido en el artículo 173 de la Constitución] constituye una consolidación de un proceso que arranca a fines de los años cincuenta del siglo pasado [...]. Desde ese pretérito, el sistema ecuatoriano se ha caracterizado por reconocer la existencia de las vías [administrativa y judicial de impugnación], debiéndose advertir que anteriormente era forzoso agotar la vía administrativa para proseguir luego con la contenciosa; y, que hoy ya no lo es, pues a partir de los tempranos noventa, se produjo una reforma que permite al particular [...], a su arbitrio, directamente, acudir ante los jueces contra las actuaciones de la administración (Troya Jaramillo 2014, 79).

A esa fecha, la justicia contencioso-administrativa estaba conformada por tribunales de única instancia, distribuidos en número de siete para todo el país -si bien algunos tenían más de una sala- y sustanciaban las causas en un proceso que no preveía la suspensión cautelar de los actos impugnados (Velasquez Baquerizo 1995, 16). 
Sin entrar en demasiados detalles, es posible entrever por qué una vía jurisdiccional a cargo de varios jueces ordinarios que ya funcionaban en el país, asentados en cada cantón, podría parecer mejor para cumplir con la labor de proveer a las ciudadanas y ciudadanos de

... un recurso sencillo y rápido o [...] efectivo ante los jueces y tribunales competentes, que [los] ampare contra actos que violen sus derechos fundamentales reconocidos por la Constitución, la ley o la [Convención Americana sobre Derechos Humanos], aun cuando tal violación sea cometida por personas que actúen en ejercicio de sus funciones oficiales (Convención Americana sobre Derechos Humanos 1978, artículo 25.1.).

José Vicente Troya, sin embargo, reivindica el valor de la jurisdicción contencioso administrativa como mecanismo de protección de los derechos reconocidos en la Constitución de la República. En concreto, señala:

El derecho de los particulares de impugnar ante la justicia los actos administrativos que le son lesivos es garantía de categoría constitucional. Se trata de una verdadera acción, no de un recurso, pues se propone no como una nueva alzada ante el juez, sino como un arbitrio al que acude el particular con independencia del actuar de la administración. Se trata de un nuevo juicio propuesto por el administrado cuyos derechos subjetivos ha visto lesionados (Troya Jaramillo 2014, 80).

Este es un criterio muy similar al de Sustein y Holmes, quienes hacen notar que el acceso a todos los órganos jurisdiccionales es una precondición para la existencia del Estado de Derecho, desde su versión más clásica. Así, indican que “[1]os más conocidos agentes gubernamentales de [...] defensa de derechos son los propios tribunales. [...] El libre acceso al poder judicial y la apertura a apelaciones son el punto culminante de la construcción del Estado liberal" (Holmes y Sunstein 2012, 65).

La decisión del constituyente está, entonces, en atacar las causas estructurales de violación sistemática de los derechos constitucionales por un sistema de administración de justicia que, desde su diseño, resulta ineficiente, o fortalecer un sistema de administración de justicia constitucional paralelo que, en ciertos casos y bajo ciertas circunstancias, sirva para solventar las deficiencias del sistema general - esto, al menos en el discurso oficial que defiende la expansión-. David Kennedy efectúa una crítica contra el movimiento internacional de los derechos humanos, la cual puede ser enfilada sin mucho esfuerzo a nuestro tema de discusión. El autor indica que el movimiento "[mantiene al fondo el segundo plano]" -la expresión que utiliza en lengua inglesa es "backgrounding the background".(Kennedy 2002, 110) Así, señala que 


\section{LAS CONSECUENCIAS DE LAS DECISIONES DEL CONSTITUYENTE EN LAS FINANZAS PÚBLICAS: EL CASO DE LAS JURISDICCIONES PARALELAS}

[los efectos de un amplio conjunto de normas que no explícitamente condenan violaciones pero que sin embargo afectan la incidencia de la violación en una sociedad son dejada sin atender. Como resultado, estas normas de fondo -que pueden ser más importantes en generar daño que la ausencia de derechos y remedios para las víctimas- son dejadas sin asignarles culpa] (Kennedy 2002, 110). ${ }^{4}$

En otras palabras, el tratar de solucionar los problemas de acceso y protección efectiva de los derechos e intereses por medio de la creación y fortalecimiento de un régimen paralelo, más tuitivo y menos accidentado, no se diferencia en mucho de la actitud de quien esconde la basura debajo de la alfombra.

Ahora bien, es necesario también considerar que por cada vez que el constituyente originario o derivado decidió expandir el ámbito de protección de la garantía, tanto el legislador ordinario, por medio de la promulgación de las leyes en la materia;(Ley de Control Constitucional 1997; Tribunal Constitucional del Ecuador, s. f.; Ley Orgánica de Garantías Jurisdiccionales y Control Constitucional 2009, artículo 42. 3)5 como la Corte Suprema de Justicia, a través de resoluciones encaminadas a "interpretar" en caso de "duda u oscuridad de las leyes" (Corte Suprema de Justicia 2001, 2002a, 2002b; Tribunal Constitucional del Ecuador, s. f.) $;^{6}$ e incluso, el hoy extinto Tribunal Constitucional, en su jurisprudencia (ver Oyarte Martínez 2006, 14); ${ }^{7}$ se dedicaron sistemáticamente a la tarea de reducir el ámbito de aplicación y las posibilidades de hallar remedio eficaz por medio de la acción.

Respecto del legislador ordinario, no es de extrañar que busque limitar el poder de la jurisdicción constitucional, a pesar de que respecto de las acciones de amparo y de protección no sea -en la mayoría de casos- el poder legislativo aquel del que emanen los actos impugnados. Con relación a la Corte Suprema de Justicia, la cuestión es más polémica y en su momento despertó debate, tanto en relación a la competencia del tribunal de casación para

\footnotetext{
${ }^{4} \mathrm{El}$ texto original, en idioma inglés, señala: "The effects of a wide array of laws that do not explicitly condone violatios but nevertheless affect the incidence of violation in a society are left unattended. As a result, these background laws -which may well be more important in generating the harm than an absence of rights and remediesfor victims- are left with clean hands".

${ }^{5}$ En la Ley de Control Constitucional,por ejemplo, constaba la disposición que ordenaba que las resoluciones en las que se concedía la acción sean objeto de consulta obligatoria ante el Tribunal Constitucional. la disposición fue derogada por decisión del Tribunal Constitucional. Por su parte, el artículo 42.3 de la Ley Orgánica de Garantías Jurisdiccionales y Control Constitucional prohíbe la presentación de la acción de protección, entre otros supuestos, «[c]uando el acto administrativo pueda ser impugnado en la vía judicial, salvo que se demuestre que la vía no fuere adecuada ni eficaz».

${ }^{6}$ La última última de las resoluciones de la Corte Nacional de Justicia fue declarada inconstitucional por el Tribunal Constitucional.

${ }^{7}$ El autor indica que «[s]on los fallos del máximo órgano de control constitucional los que, en gran medida, han establecido los límites de [la acción de amparo constitucional], a través de la interpretación que se la ha dado, principalmente al texto constitucional y a la Ley de Control Constitucional en materia de amparo»
}

CONPEDI LAW REVIEW | QUITO - EQUADOR | v. 4 | n. 2 | p. 128 - 145 | JUL - DEZ | 2018 
regular disposiciones constitucionales, a nombre de interpretar una ley preconstitucional; y, sobre todo, para establecer restricciones al acceso y la tutela provista por la acción de amparo constitucional (Oyarte Martínez 2006, 15 a 16; Ávila Santamaría et al. 2005, 138 y 139). En todo caso, tanto el Tribunal Constitucional, como los jueces que conocían la acción en primera instancia aceptaron sin mayores problemas las dos primeras resoluciones; esto, debido a la posición privilegiada de la Corte Suprema de Justicia en términos del capital social que poseía a la época, ya que se hallaba consolidada como órgano que determinaba el sentido del derecho y la cúspide del sistema de administración de justicia (Tribunal Constitucional del Ecuador, s. f.). En todo caso, tanto el legislador ordinario como el tribunal de casación compartían el no participar del descentramiento estructural propio del derecho constitucional como subcampo independiente del resto del derecho público.

La situación del Tribunal Constitucional era distinta. La actuación del Tribunal, estableciendo límites a la acción de amparo constitucional, es explicable si se considera el hábito de los jueces del extinto tribunal (Bourdieu 2000, 163) ${ }^{8}$ en su gran parte formados en disciplinas como el derecho administrativo. Prueba de ello es, por ejemplo, que para calificar la "ilegitimidad" de un acto impugnado por medio de la acción de amparo constitucional, hayan recurrido a la extensión de los criterios de competencia, contenido, procedimiento, causa, objeto y motivación, propios del análisis de legalidad de los actos en sede contenciosoadministrativa (Oyarte Martínez 2006, 87 a 102). En suma, a pesar de que el constituyente favoreció la fragmentación del discurso jurídico en el derecho público, su hegemonía fue pasajera y opacada con actores con mayor capital social en la disputa cotidiana por el control del discurso. Tan gravitante fue su influencia, que el discurso contencioso-administrativo colonizó con facilidad el nuevo fragmento constitucional.

Ante este contexto, y aunque "[1] as declaraciones [...] de “¿cuánto procedimiento es necesario?', pueden parecer producto del sentido común" (Holmes y Sunstein 2012, 46), no lo fueron al momento de considerar que el amparo constitucional podía generar conflictos de competencia material, en tanto su criterio de diferenciación no eran tanto los hechos, como la fuente del derecho que se considere transgredida. Menos aún lo fueron el momento en que, al diseñar las garantías jurisdiccionales en la Constitución de la República del Ecuador de 2008, el constituyente rebasó el carácter cautelar -ausente en los procesos contencioso-

\footnotetext{
${ }^{8}$ El traductor de Bourdieu explica la concepción de este último respecto del hábito como «... la formación de maneras de comprensión, de juicio y de actuación que surgen de la pertenencia de los sujetos a distintos campos sociales». 
administrativos y asumido en la práctica judicial por la acción de amparo constitucional-, y previó que

... en caso de constatares la vulneración de derechos, [la jueza o juez constitucional] deberá declararla, ordenar la reparación integral, material e inmaterial, y especificar e individualizar las obligaciones, positivas y negativas, a cargo del destinatario de la decisión judicial, y las circunstancias en que deban cumplirse" (Constitución de la República del Ecuador 2008, artículo 86).

$\mathrm{Si}$, como señala Troya, la jurisdicción contencioso-administrativa, a través del conocimiento y resolución del recurso subjetivo o de plena jurisdicción, está en la capacidad de resarcir "... toda clase de lesión de los derechos subjetivos y se refiere a cuestiones patrimoniales, a contratos a responsabilidades de la administración" (Troya Jaramillo 2014, 87), y tiene por finalidad que "[t]odos los [administrados] que ven lesionados sus derechos pued[a]n proponer reclamaciones, recursos y acciones a fin de que se repare el daño" (Troya Jaramillo 2014, 89), es claro que basta con que un derecho constitucional halle un desarrollo legislativo en la forma de un derecho subjetivo, para que se produzca el traslape de jurisdicciones, que previsiblemente terminará en la contraposición de regímenes específicos, propia del proceso de fragmentación al que se ha hecho alusión en este trabajo.

Más aún, la separación de regímenes ha ocasionado distorsiones que redundan en desprotección de los usuarios de la administración de justicia. Así, por ejemplo, de acuerdo con la Secretaría Técnica Jurisdiccional de la Corte Constitucional, al año 2013, "[e]l mayor número de acciones de protección fueron negadas, ya que de esta manera resolvieron los jueces de 671 casos, lo que representa el 83,15\%...” (Aguirre Castro y Avila Benavidez 2014, 51). La razón para negar las acciones, a esa fecha, principalmente se basó en la aplicación del siguiente obiter dictum presente en la sentencia $\mathrm{N}^{\circ} 001-10-\mathrm{PJO}-\mathrm{CC}$, que a su vez parafraseaba el texto del artículo 50 de las Reglas de Procedimiento para el Ejercicio de las Competencias de la Corte Constitucional para el Período de Transición:

La acción de protección no procede cuando se refiere a aspectos de mera legalidad, en razón de los cuales existen vías judiciales ordinarias para la reclamación de los derechos y particularmente la vía administrativa [...]. Si vía acción de protección se impugna de manera exclusiva la legalidad del acto, sin que conlleve vulneración de derechos constitucionales, el asunto debe decidirse en los mecanismos judiciales ordinarios competentes, pero no a través de una garantía jurisdiccional.

De acuerdo con el estudio indicado, “[c]uando se citó esta sentencia, en el 98,1\% las acciones fueron negadas; y, en 1,59\%, que corresponde a 1 acción, fue admitida" (Aguirre 
Castro y Avila Benavidez 2014, 51). En conclusión, las víctimas de la fragmentación del discurso jurídico son los propios titulares de los derechos que las garantías debían proteger.

\section{Las consecuencias de la fragmentación en las finanzas públicas}

Como se ha discurrido a lo largo del presente trabajo, la disponibilidad de un recurso sencillo y rápido para amparar contra violaciones de derechos fundamentales $-\mathrm{o}$, en términos de la Constitución de la República del Ecuador, el acceso a la justicia y la tutela efectiva, imparcial y expedita de los derechos e intereses (Constitución de la República del Ecuador 2008, artículo 75)- es, en sí mismo, un derecho; y, como tal, su satisfacción tiene un costo, pues “... el tiempo de los tribunales es dinero de los contribuyentes" (Holmes y Sunstein 2012, 45). ${ }^{9}$ En palabras de Holmes y Sustein, “[a] la verdad evidente de que los derechos dependen de los gobiernos es preciso agregar un corolario lógico, rico en implicaciones: los derechos cuestan dinero. Es imposible protegerlos o exigirlos sin fondos y apoyo público" (Holmes y Sunstein 2012, 33).

Considerar la administración de justicia como un asunto de gasto público parecería ser lo más adecuado, debido a los altos costos que implica mantener todo un aparato de administración de justicia, sin considerar los costos asumidos por los propios usuarios:

[Los] gastos operativos [de la administración de justicia] se pagan con ingresos fiscales canalizados con éxito hacia los tribunales y sus funcionarios [...]. Ningún tribunal puede funcionar sin recibir con regularidad inyecciones de dinero de los contribuyentes para financiar sus esfuerzos por disciplinar a los violadores de las leyes [...] (Holmes y Sunstein 2012, 65).

Lo dicho cobra aún más relevancia si consideramos que la fuente de gasto público son los bolsillos de los propios ciudadanos. Esto lo hace notar Eddy de la Guerra -aunque podemos decir, utiliza la definición de Alexy de derecho a prestación, la cual no parece un poco limitada para el presente análisis, pues, como se podrá inferir para este momento, el autor del presente trabajo considera que el acceso a la justica y la tutela judicial efectiva, imparcial y expedita también entran en esa categoría-:

De forma que los tributos recaudados a través del sistema tributario justo, además de medios para obtener recursos públicos, son [...] instrumentos de la política fiscal y por ende, de la justicia distributiva; en calidad de prestaciones patrimoniales de orden público, permiten

\footnotetext{
${ }^{9}$ En países como Ecuador, aún más relevante sería considerar que el dinero viene, además de los tributos, de la explotación de nuestros recursos naturales no renovables, lo que llama incluso a considerar el impacto en términos de desprotección de los derechos de la naturaleza. 


\section{LAS CONSECUENCIAS DE LAS DECISIONES DEL CONSTITUYENTE EN LAS FINANZAS PÚBLICAS: EL CASO DE LAS JURISDICCIONES PARALELAS}

satisfacer necesidades vitales reconocidas en la Constitución, en la forma jurídica de derechos económicos y sociales. Así [...] derechos denominados prestación como derechos a prestaciones en sentido estricto se cumplen mediante la prestación efectiva de servicio y son de acceso general, gracia a la distribución equitativa y priorización del gasto público (De la Guerra Zúñiga 2018, 307).

Troya hace notar que es necesario que exista una conciencia de la "relación" existente entre las normas constitucionales y los recursos necesarios para hacerlas efectivas. Así, propone entre los principios que destaca, el de eficiencia, que no es sino la maximización de resultados con un mínimo de recursos. Adicionalmente, identifica que

[e]n el caso ecuatoriano, vale decir, en el derecho del gasto público del país, habría que tener presente dos principios irreductibles, cuales son la solidaridad y la necesaria planificación. [...] Estos principios, junto a los de legalidad, equidad y eficacia, han de configurar un haz armónico que sustantiviza este ramo jurídico (Troya Jaramillo 2014, 194 y 195).

Así, junto con la eficiencia, también debe ser considerara la eficacia. Esta implica que los recursos utilizados cumplan con los fines para los que fueron destinados.

Tanto el principio de eficiencia como el de eficacia se ven afectados el momento en que la fragmentación del discurso jurídico de la relación ciudadano-Estado se traslada al plano institucional. Primero, porque el Estado se ve obligado a financiar ambos sistemas, lo que “... cuesta $[\ldots]$, como mínimo, reclutar, entrenar, equipar, pagar y (a su vez) monitorear a los custodios judiciales de nuestros derechos básicos" (Holmes y Sunstein 2012, 65). Segundo, porque hace que los usuarios dupliquen sus gastos de defensa profesional -lo que, a su vez, compromete su capacidad económica, disminuye su poder adquisitivo y termina por minar la cantidad de ingresos del propio Estado-. Por último, porque genera inseguridad respecto de los resultados del litigio, la que posteriormente desemboca en complicaciones a la hora de ejecutar decisiones jurisdiccionales, las que en muchos casos comportan el pago de dinero que también sale de los bolsillos de los contribuyentes.

\section{Conclusión}

Como se ha discurrido en el presente trabajo, la creación y expansión de la protección constitucional por medio del amparo constitucional -posteriormente separado en la solicitud de medidas cautelares, la acción de protección y la acción extraordinaria de protección-, pueden ser vistas como la imposición de una solución-parche, que funcione como una muleta para una justicia contencioso administrativa que históricamente ha sido diseñada $\mathrm{y}$ ha 
funcionado de forma deficiente y son los recursos económicos, humanos y jurídico-procesales para servir como un freno eficaz en contra de la arbitrariedad en el ejercicio del poder.

La afirmación consignada en el párrafo precedente podría extenderse a otros campos de lo que se ha denominado como la justicia ordinaria. Un examen que abarque todos los pontos de intersección, sin embargo, requeriría un esfuerzo que excede con creces el alcance del presente trabajo. Sin embargo, queda sobre la mesa la siguiente advertencia:

... es imposible explorar por completo las dimensiones morales de la protección de los derechos sin considerar la cuestión de la justicia distributiva. Después de todo, con frecuencia ocurre que los recursos provistos por la colectividad son canalizados, sin ninguna razón válida, hacia la protección de los derechos de algunos ciudadanos y no de otros.

En general, los derechos se exigen a través de tribunales que funcionan normalmente y que disponen de fondos adecuados (Holmes y Sunstein 2012, 36 y 37).

Por lo pronto, se pueden extraer las siguientes conclusiones: Primero, la existencia de un proceso de fragmentación del discurso jurídico en torno a la relación ciudadano-Estado permite evidenciar que, ante una miríada de caminos de remedio jurisdiccional, la protección de los derechos se diluye en discusiones relacionadas con la competencia material para resolver el asunto. Por tanto, corresponde preguntarse si la mera inclusión de una garantía jurisdiccional -o varias- efectivamente sirve para proveer de mayor protección a los sujetos de derechos, si quienes deben aplicar el discurso encaminado a su protección son hablantes natos y están condicionados por el discurso propio de la justicia ordinaria; y, si primero no se hace esfuerzos para que dicho discurso se adecuadamente colonizado por el del derecho constitucional y no a la inversa. ${ }^{10}$ Por otro lado, la decisión de dotar de recursos para la garantía de un derecho, como el acceso a los órganos jurisdiccionales para proveerse de protección -el cual, además, es instrumental respecto de otros derechos que de forma más evidente hacen referencia a la procura de recursos para la satisfacción de necesidades básicas, implica inexorablemente una opción política consistente en dejar desatendidos otros. Por último, la proliferación de las garantías jurisdiccionales de los derechos constitucionales como procesos independientes, alternativos y paralelos a los ya existentes, no necesariamente puede

\footnotetext{
${ }^{10}$ El término "adecuadamente" se halla resaltado, debido a que también se puede observar una utilización de la "gramática" de un discurso, pero no del discurso propiamente dicho. Esta suerte de abuso del discurso de puede observar, por ejemplo, cuando el legislador decide "constitucionalizar" la ley penal por medio de la tipificación técnicamente inadecuada y profundamente imprecisa de delitos como el de discriminación. En el artículo 176 del Código Orgánico Integral Penal, por ejemplo, el legislador efectúa un parafraseo del artículo 11. 2 de la Constitución de la República para convertir todo acto discriminatorio -o incluso acto de propaganda o incitación a la discriminación- en infracción punible con uno a tres años de prisión, o de tres a cinco años si el autor es un servidor o servidora pública, sin que importe el grado de lesión al bien jurídico protegido.
} 
verse como la decisión más sabia, sobre todo si se considera que los derechos cuestan y gastar en ellos de forma ineficiente no se diferencia mucho de dilapidar el salario de un mes en una sola borrachera.

\section{Referencias}

Aguirre Castro, Pamela Juliana, y Dayana Fernanda Avila Benavidez, eds. 2014. Garantías jurisdiccionales: análisis cuantitativo de las decisiones de los jueces de instancia y apelación en el año 2013. Jurisprudencia constitucional, no 5. Quito, Ecuador: Centro de Estudios y difusión del Derecho Constitucional (CEDEC).

Andrade Ubidia, Santiago. 2001. «Intervención: Mesa redonda: Los actos administrativos en el amparo». En Guía de litigio constitucional, 2:71 a 109. Quito: Corporación Latinoamericana para el Desarrollo.

Ávila Linzán, Luis. 2011. «El hábeas corpus en un Estado constitucional de derechos y justicia». En Apuntes de Derecho Procesal Constitucional, editado por Juan Montaña Pinto y Angélica Porras Velasco, 2:153 a 178. Quito: Corte Constitucional para el período de Transición.

Ávila Santamaría, Ramiro, Mercedes Cóndor Salazar, Gabriela Espinosa Serrano, Daniel Gallegos Herrera, Efrén Guerrero Salgado, Fidel Jaramillo Paz y Miño, Carla Patiño Carreño, José Valencia Amores, y Clínica de Derechos Humanos de la Pontificia Universidad Católica del Ecuador. 2005. «El Estado social de Derecho en Ecuador: Un país en crisis». Ruptura, n. ${ }^{\circ}$ 49.

Bourdieu, Pierre. 2000. «Elementos para una Sociología del Campo Jurídico». En La Fuerza del derecho, de Pierre Bourdieu y Gunther Teubner, traducido por Morales de Setién Ravina Cerlos, 153 a 220. Santafé de Bogotá, Colombia: Uniandes.

Código Orgánico General de Procesos. 2015.

Constitución de la República del Ecuador. 2008.

Constitución Política de la República del Ecuador. 1967.

—. Constitución Política de la República del Ecuador. 1996.

—. Constitución Política de la República del Ecuador. 1998.

Convención Americana sobre Derechos Humanos. 1978.

Corte Suprema de Justicia. 2001. Resolución $N^{\circ} 1$.

- 2002a. Resolución $N^{\circ} 2$.

2002b. Resolución $N^{\circ} 3$.

De la Guerra Zúñiga, Eddy. 2018. El deber de contribución al gasto público. Principios que lo informan y derechos del contribuyente. México D. F.: Porrúa.

Eco, Umberto, y Umberto Eco. 2011. The Name of the Rose. Traducido por William Weaver. Boston: Houghton Mifflin Harcourt.

http://banq.lib.overdrive.com/ContentDetails.htm?id=DA9EF467-F633-4484-8023-

B4B0121CD78C. 
Ferrajoli, Luigi. 2007. Principia Iuris. Teoría del derecho y de la democracia. Vol. 1. Madrid: Trotta.

Gallegos Herrera, Daniel. 2016. «Should We All Get Accustomed to It? The Ecuadorian Experience and Position Concerning Foreign Investment Protection Under International Law». Revista JurisDictio 17: 119 a 161.

2018. «Una actitud posmoderna en relación al Derecho (o Eco y Koskenniemi aplicados al Derecho Constitucional)». Trabajo de Epistemología y método para el derecho y las ciencias sociales, Quito: Universidad Andina Simón Bolívar - Sede Ecuador.

Holmes, Stephen, y Cass R Sunstein. 2012. El costo de los derechos: por qué la libertad depende de los impuestos. Buenos Aires: Siglo XXI Editores.

Kennedy, David. 2002. «The International Human Rights Movement: Part of the Problem?» Harvard Human Rights Journal 15: 102 a 125.

Koskenniemi, Martti. 2011a. «Between Apology and Utopia: The Politics of International Law». En The Politics of International Law, 35 a 62. Oxford; Portland, Or: Hart Publishing.

- 2011b. «International Law and Hegemony: a Reconfiguration». En The Politics of International Law, 219 a 240. Oxford; Portland, Or: Hart Publishing.

- 2011c. The politics of international law. Oxford ; Portland, Or: Hart. 2011d. «The Politics of International Law - 20 Years Later». En The Politics of International Law, 63 a 76. Oxford; Portland, Or: Hart Publishing.

Laclau, Ernesto. 2004. «Discurso». Nueva Época 2 (68): 7 a 18.

Ley de Control Constitucional. 1997.

Ley de la Jurisdicción Contencioso Administrativa. 1968.

Ley Orgánica de Garantías Jurisdiccionales y Control Constitucional. 2009.

Marks, Susan. 2010. «False Contingency». Current Legal Problems 62: 1-22.

Oyarte Martínez, Rafael. 2006. La acción de amparo constitucional: jurisprudencia, dogmática y doctrina. Quito: Andrade \& Asociados.

Tribunal Constitucional del Ecuador. s. f. Resolución N 0005-2003-TC.

- s. f. Resolución $N^{\circ}$ 036-2001-TC.

—. s. f. Resolución N 184-2000-TP.

Troya Jaramillo, José Vicente. 2014. El Derecho del gasto público - Especial referencia a los derechos económicos, sociales y políticos. Bogotá: Temis.

Velasquez Baquerizo, Ernesto. 1995. La nueva justicia administrativa: Diagnóstico del Derecho Contencioso Administrativo y Fiscal en el Ecuador. Quito: Corporación Latinoamericana para el Desarrollo.

Zabala Egas, Jorge. 2001. «Acción de Amparo Constitucional». En Guía de litigio constitucional, 2:71 a 109. Quito: Corporación Latinoamericana para el Desarrollo. 